\title{
A INTERNAÇÃO DE ADOLESCENTES PELA LENTE DOS TRIBUNAIS
}

\author{
Maria Auxiliadora Minahim e Karyna Batista Sposato
}

\section{RESUMO}

Desde sua entrada em Vigor, o Estatuto da CRiança e do Adolescente SOFRE SISTEMÁtICAS CRítICAS NO DEBATE PÚBlICO, NÃO HAVENDO, ENTRETANTO, NO CAMPO DA DOUTRINA ESPECIALIZADA E DA JURISPRUDÊNCIA EFETIVOS ESFORÇOS PARA UMA COMPREENSÃO DO ALCANCE DA LEI E DE SEUS PRINCÍPIOS, SOBRETUDO QUANDO O TEMA É A IMPOSIÇĀO DE MEDIDAS DE INTERNAÇÃO A ADOLESCENTES AUTORES DE INFRAÇÃO PENAL. ESTE TEXTO PROCURA DEMONSTRAR A FEIÇÃO HOMOGÊNEA E ESTÁVEL DA JURISPRUDÊNCIA BRASILEIRA NOS TRIBUNAIS ESTADUAIS NESSA MATÉRIA À LUZ DOS PRINCIPAIS ARGUMENTOS UTILIZADOS COMO FUNDAMENTAÇÃO DAS DECISÕES EM SEDE RECURSAL. Alguns RESUltados da PESQUisa "Responsabilidade E GARANTIAS AO ADOLESCENTE AUTOR DE ATO INFRACIONAL: UMA PROPOSTA DE REVISÃO DO ECA EM SEUS 18 ANOS DE VIGÊNCIA", apolada PELA SECRETARIA dE AsSuntos Legislativos dO MinistérIo da JUSTIÇA, ILUSTRAM AS DIFICULdADES DE IMPLEMENTAÇÃO DOS PRECEITOS LEGAIS, POSSIBILITANDO REFLETIR SE É A TEXTURA ABERTA DA LEI O QUE VEM FAVORECENDO A PERSISTÊNCIA DE ARGUMENTOS EXTRAJURÍDICOS E IDEOLÓGICOS EM SUA INTERPRETAÇÃO.

\section{PALAVRAS-CHAVE}

Estatuto da Criança e do Adolescente, Medida de Internação, Direito Penal Juvenil, Devido Processo LEgAL, INTERPRETAÇÃO DO DIREITO

\section{ABSTRACT}

SinCE ITS aPPROVAL, THE CHILd AND AdOLESCENT ACT HAS BEEN ATTACKED FOR SEVERAL CRITICS IN THE PUBLIC DEBATE. HOWEVER NEITHER THE SPECIALIZED DOGMATIC NOR JURISPRUDENCE HAVE PRESENTED EFFECTIVE EFFORTS TO THE COMPREHENSION OF THE LAW OR ITS PRINCIPLES, ESPECIALLY RELATED TO INTERNMENT MEASURES APPLIED TO YOUNG OFFENDERS. THE TEXT SHOWS THE HOMOGENEOUS APPEARANCE OF THE BRAZILIAN JURISPRUDENCE INTO THE STATE COURTS, ACCORDING TO THE MOST USED ARGUMENTS BY THE DECISIONS. SOME RESULTS FROM THE

"RESPONSIBILITY AND GUARANTEES TO YOUNG OFFENDER: A REVISION PROPOSAL FOR THE CHILD AND ADOLESCENT ACT IN 18 YEARS OF EXISTENCE" RESEARCH ILLUSTRATE THESE DIFFICULTIES TO IMPLEMENT THE LEGISLATION, AVOIDING THE CONSIDERATION REGARDING THE OPEN TEXTURE OF THE LAW AS A POSSIBLE CAUSE FOR THE PERSISTENCE OF EXTRALEGAL AND IDEOLOGICAL ARGUMENTS ON ITS INTERPRETATION.

\section{KEYWORDS}

THE ChILd AND Adolescent ACt, INTERnMENT MEAsure, JUVENILE CRIMINAL LAW, DUO PROCESS OF LAW, LAW INTERPRETATION

\section{INTRODUÇÃO}

O presente artigo analisa a feição homogênea e estável da jurisprudência brasileira nos Tribunais Estaduais em matéria de medidas de privação de liberdade aplicadas a 
adolescentes, ${ }^{1}$ à luz dos principais argumentos utilizados como fundamentação das decisões em sede de recursos.

Uma possível e preliminar tentativa de explicação mora na constatação de que em que pesem as diferentes possibilidades interpretativas ${ }^{2}$ disponíveis, o trabalho do juiz é, na maioria dos casos, a adoção de uma espécie de "regra do jogo". ${ }^{3}$ Tal regra inicia-se com a concepção fictícia de um legislador racional e único e culmina na pretensão de alcançar um consenso também racional. À guisa de aprofundar a discussão, o tema do auditório universal de Perelman é, nesse sentido, bastante significativo, assim como suas noções de consenso e opinião pública.

Por tratar da imposição de medidas de privação da liberdade, o objeto central da análise que apresentaremos é a Lei n. 8.069/90, o Estatuto da Criança e do Adolescente (ECA), em seus 20 anos de vigência e interpretação. Desde sua entrada em vigor, vale dizer, o ECA vem sofrendo sistemáticas críticas. ${ }^{4}$ Um dos desafios é justamente identificar quais são as principais lacunas da legislação que dão margem a arbitrariedades, à utilização de argumentos extrajurídicos na solução de casos e, em consequência, sua recorrente desqualificação no debate público.

Mais que isso, trata-se de indagar se as dificuldades para conferir efetividade aos preceitos legais se referem à textura aberta da lei $^{5}$ ou a outros motivos que de modo bastante contundente vêm condicionando a interpretação do Estatuto e conferindo uma feição quase unânime em seu padrão decisório.

A partir de alguns dos resultados obtidos na Pesquisa "Responsabilidade e Garantias ao adolescente autor de ato infracional: uma proposta de revisão do ECA em seus 18 anos de vigência", realizada pela Universidade Federal da Bahia (UFBA) ${ }^{6}$ no âmbito da linha de pesquisa Estatuto da Criança e do Adolescente: apuração do ato infracional atribuído a adolescente do Projeto Pensando o Direito, Edital $01 / 2009$ da Secretaria de Assuntos Legislativos do Ministério da Justiça, procuraremos responder algumas interrogações.

A pesquisa em questão partiu da análise de dados coletados junto aos Tribunais de Justiça dos Estados de São Paulo, Pernambuco, Rio Grande do Sul, Rio de Janeiro, Paraná e Bahia, e ao Superior Tribunal de Justiça (STJ), em matéria de medida socioeducativa de internação no período de janeiro de 2008 a julho de 2009 e, posteriormente, da observação de casos junto às varas da infância e juventude de São Paulo, Porto Alegre, Recife e Salvador. ${ }^{7}$ De plano, pôde-se constatar que a medida de internação é sistematicamente imposta com baixa fundamentação legal, e em não poucos casos sem a devida consideração dos requisitos legais exigidos pelo Estatuto da Criança e do Adolescente.

Nesse cenário, revelou-se a dupla crise que Emilio Garcia Mendez refere e que afeta o Estatuto da Criança e do Adolescente de forma bastante incisiva, ${ }^{8}$ ou seja, as normas estatutárias estão expostas a uma crise de interpretação e de igual maneira a uma crise de implementação. Alguns eufemismos que perpassam a legislação como 
um todo - em especial, a definição da medida privativa de liberdade como internação em estabelecimento educacional (art. 116 do ECA) -, favorecem que sua imposição não seja limitada pelos princípios do contraditório, da proporcionalidade, da lesividade e até mesmo da legalidade - princípios indispensáveis quando é a liberdade do indivíduo que está em jogo. A falsa percepção de que a medida de internação constitui-se em uma "benesse" e reveste-se de caráter protetivo ${ }^{9}$ afasta sua verdadeira índole penal e, consequentemente, os limites ao poder de punir que deveriam ser exercitados nesse campo.

Para Garcia Mendez, a crise de interpretação do ECA não possui natureza técnica, ela está vinculada à persistência das "boas” práticas tutelares e compassivas, ou seja, vincula-se a uma cultura aparentemente progressista, que em realidade é messiânica, altamente subjetiva e discricionária.

A análise aqui apresentada tomará como referência a hermenêutica histórica nos moldes do que Gadamer propõe: as características inerentes "do lugar e do contexto" nos quais se encontra o intérprete devem ser levadas em conta, sendo que a consciência da história efeitual ${ }^{10}$ é em primeiro lugar a consciência da situação hermenêutica. Esse é um dos aspectos centrais desta reflexão, o que nos permite confrontar os principais espaços de resistência na aplicação do ECA, desde a linguagem até a concepção de adolescência e de delinquência na adolescência. Trata-se de atentar para a dimensão cultural e o contexto no qual a lei incide como elemento determinante da realidade interpretativa que rodeia o ECA.

A implementação das sentenças de internação pela Justiça Especializada da Infância e Juventude em todo o país demonstra uma inequívoca carência de aprofundamento doutrinário e a presença marcante de argumentos extrajurídicos e ideológicos.

Nessa dimensão, a pesquisa se combina aos objetivos deste artigo, na medida em que pode ser caracterizada como uma modalidade de sentencing, 11 ou seja, tem como foco a análise de decisões judiciais a partir de uma perspectiva sociológica e criminológica, que permite verificar a atuação do sistema de justiça na trama social, na reprodução de desigualdades, na reificação dos sujeitos envolvidos, na renovação de preconceitos e identificação com o senso comum. Permite ainda analisar sob a influência de qual método ou teoria interpretativa vem se desenhando o padrão decisório neste campo do Estatuto da Criança e do Adolescente.

Não por acaso as repetidas críticas endereçadas ao Estatuto da Criança e do Adolescente também repousam em juízos de valor popularmente difundidos em torno da prática de infrações penais por adolescentes e sua capacidade de responder jurídica e penalmente por seus atos, o que é pano de fundo de velhas e novas propostas de redução da idade de responsabilidade penal. O discurso dominante, distorcido e sensacionalista de que os adolescentes estão cada vez mais violentos, e que cresce exponencialmente o número de adolescentes e jovens envolvidos com a criminalidade 
no país ${ }^{12}$ reforçam não só um sentimento de impunidade perante os crimes cometidos por adolescentes, como alimentam o cíclico debate em torno da redução da idade penal. ${ }^{13} \mathrm{~A}$ isto se soma o não reconhecimento de que as medidas socioeducativas previstas no Estatuto da Criança e do Adolescente sejam sanções penais, e que a justiça da infância e juventude em matéria infracional, na condição de justiça especializada, atribua responsabilidade penal aos adolescentes, contribuindo para a compreensão distorcida do sistema.

Se tais "sentimentos" e percepções podem ser encontrados no funcionamento do Sistema de Justiça Especializada da Infância e Juventude e nas instâncias superiores, há de se indagar em que medida é a lei que assim o permite, e quais seriam as possibilidades de superação. ${ }^{14}$

\section{A MEDIDA DE INTERNAÇÃO PELA LENTE DOS TRIBUNAIS}

É importante assinalar que a pesquisa em questão não se centrou unicamente na análise de discursos, mas cuidou de verificar os recursos impetrados e seus resultados, além da realização da observação de audiências junto a varas especializadas como parte da metodologia qualitativa. Por ora, cuidaremos de alguns exemplos de discursos frequentemente utilizados na fundamentação das sentenças de imposição de medida socioeducativa de internação.

É necessário detalhar que a medida socioeducativa de internação corresponde a uma das possíveis medidas aplicáveis a adolescentes diante do cometimento de infrações penais pela Justiça Especializada da Infância e Juventude nas Varas Especiais de primeira instância. ${ }^{15}$ Os discursos em análise foram retirados de recursos de segundo grau interpostos perante os Tribunais Estaduais com a finalidade de rever a sentença originariamente imposta pelo juiz singular.

A medida socioeducativa de internação está definida no art. 122 do Estatuto da Criança e do Adolescente, e corresponde à mais grave das medidas socioeducativas, pelo grau de interferência na esfera de liberdade individual dos jovens. Dispõe a lei:

A internação constitui medida privativa da liberdade, sujeita aos princípios de brevidade, excepcionalidade e respeito à condição peculiar de pessoa em desenvolvimento.

$\S 1^{\circ}$ Será permitida a realização de atividades externas, a critério da equipe técnica da entidade, salvo expressa determinação judicial em contrário.

$\S 2^{\circ} \mathrm{A}$ medida não comporta prazo determinado, devendo sua manutenção ser reavaliada, mediante decisão fundamentada, no máximo a cada seis meses.

$\S 3^{\circ} \mathrm{Em}$ nenhuma hipótese o período máximo de internação excederá a três anos. $\S 4^{\circ}$ Atingido o limite estabelecido no parágrafo anterior, o adolescente deverá ser liberado, colocado em regime de semiliberdade ou de liberdade assistida. 
$\S 5^{\circ}$ A liberação será compulsória aos 21 (vinte e um) anos de idade.

$\S 6^{\circ}$ Em qualquer hipótese a desinternação será precedida de autorização judicial, ouvido o Ministério Público.

A medida de internação consiste em real e efetiva privação de liberdade em estabelecimento destinado a adolescentes, porém assemelhado aos estabelecimentos prisionais, dadas suas características de instituição total. Trata-se do que Sotomayor identificou como estabelecimentos que se diferenciam das prisões apenas pelo rótulo externo. ${ }^{16}$

Como decorre da disposição legal estatutária, a medida de internação não poderá exceder três anos, mas sua imposição é indeterminada, sujeita a periódica reavaliação pelo Setor Técnico das unidades de privação de liberdade.

É razoável afirmar que o princípio da Brevidade é o elemento norteador para a indeterminação do prazo na medida de internação. Sua incidência no processo de execução da medida se dá pelo reconhecimento de que cada adolescente terá um desenvolvimento único e peculiar às suas características pessoais. Sem tal reconhecimento, as finalidades da medida não serão atingidas e estarão sempre fadadas à imposição de mero castigo.

No tocante à escolha da medida de internação como a mais adequada, é também o art. 122 que deve ser observado:

A medida de internação só poderá ser aplicada quando:

I. tratar-se de ato infracional cometido mediante grave ameaça ou violência à pessoa;

II. por reiteração no cometimento de outras infrações graves; e

III. por descumprimento reiterado e injustificável da medida anteriormente imposta.

$\S 1^{\circ} \mathrm{O}$ prazo de internação na hipótese do inciso III deste artigo não poderá ser superior a 3 (três) meses.

$\S 2^{\circ}$ Em nenhuma hipótese será aplicada a internação, havendo outra medida adequada.

A redação do art. 122 conduz à verificação de pressupostos ou condições objetivas para a imposição da medida. São eles: A grave ameaça ou violência à pessoa no cometimento do ato infracional; reiteração no cometimento de outras infrações graves; ou descumprimento reiterado e injustificável de medida anteriormente imposta.

Ressalte-se ainda que o parágrafo $2^{\circ}$ do referido artigo é taxativo ao estabelecer que em nenhuma hipótese será aplicada a internação, havendo outra medida adequada. Resta seu caráter altamente aflitivo e, portanto, de último recurso a ser utilizado. Assim sendo, mesmo que as circunstâncias do ato infracional correspondam às condições 
descritas no art. 122, isso não significa escolha e autorização imediatas e automáticas da medida de internação.

Não é a simples alusão à gravidade do ato praticado que determina a escolha da medida privativa de liberdade. A imposição da internação somente é admitida da conjunção de todos os elementos e não somente da verificação se o ato é grave. Nessas situações, a internação é permitida, mas não obrigatória. Em outras sequer seria admitida como resposta socioeducativa.

Sobre a adequação da medida de internação e sua natureza excepcional, vale mencionar as lições de Paulo Garrido:

O traço de instrumentalidade da tutela diferenciada consiste na concepção de que a medida socioeducativa serve como instrumento de defesa social, ao mesmo tempo em que se consubstancia como meio de intervenção no desenvolvimento do jovem. Do cotejo dos elementos dessa instrumentalidade é que se extrai a adequação da medida socioeducativa a ser definida no caso concreto, não guardando relação direta com o ato infracional praticado. Por isso o legislador não vinculou diretamente certo ato infracional com determinada medida socioeducativa, ficando sempre ao encargo da autoridade judiciária compor os elementos da instrumentalidade, à luz das particularidades do caso concreto. ${ }^{17}$

As lições de Garrido reforçam o entendimento de que a imposição de qualquer medida socioeducativa implica a integração e a observância de todos os princípios que informam o Direito Penal Juvenil. ${ }^{18} \mathrm{E}$, em se tratando das medidas privativas de liberdade, mais intensa é essa necessidade, a fim de adequar devidamente cada resposta ao caso concreto -, por isso os princípios da brevidade, excepcionalidade e respeito à condição peculiar de desenvolvimento do adolescente:

As limitações impostas pelo Estatuto da Criança e do Adolescente dizem respeito tão somente às medidas de internação e de colocação em casa de semiliberdade, restringindo a discricionariedade da autoridade judiciária em favor do adolescente, prescrevendo regra de possibilidade e não incidência obrigatória. ${ }^{19}$

Assim sendo, a privação de liberdade somente é cabível ante a verificação dos pressupostos objetivos e como condição necessária para que se realize a socioeducação do adolescente. ${ }^{20}$ A restrição da liberdade deve significar apenas limitação do exercício pleno do direito de ir e vir e não de outros direitos constitucionais.

Alguns trechos de decisões extraídas da pesquisa retromencionada podem ilustrar as principais tendências jurisprudenciais sobre a matéria a partir dos discursos mais 
frequentemente utilizados. No Tribunal de Justiça de São Paulo, tomando o recorte temporal da pesquisa, foram identificadas 42 ocorrências sobre medida socioeducativa de internação, das quais 40 foram analisadas. Do universo amostral destacam-se alguns posicionamentos que aparecem inclusive de forma repetida nas fundamentações e, sendo bastante simbólicos, permitem identificar uma tendência interpretativa:

A prática de gravíssimo ato infracional denota desajuste moral e social, e, portanto, a manutenção das medidas socioeducativas de liberdade assistida e prestação de serviços à comunidade não se apresentam suficientes à ressocialização do apelado, que, em liberdade, poderá expor a incolumidade física de terceiros a risco. Há nítida relação de proporcionalidade entre a aplicação da internação - perseguida pelo apelante -, e o ato infracional praticado pelo apelado [...]. De outra banda, convém anotar que o apelado não tem respaldo familiar, revelou - ainda que informalmente -, o envolvimento em outros atos infracionais (fls. 59), e, durante o curso processual não demonstrou exercício de ocupação lícita, permitindo concluir que não possui estrutura para o cumprimento, a contento, das medidas socioeducativas impostas pela sentença apelada.

Nesse julgado, observam-se três aspectos importantes: a correlação da prática de ato infracional grave com a existência de desajuste social e moral, demonstrando uma visão estereotipada dos adolescentes acusados e sentenciados, e a criação de uma categoria explicativa com fundamento moral; a utilização do princípio da proporcionalidade na justificação da internação, de forma automática, ou seja, se grave a conduta, a internação encontra-se justificada em desconsideração à necessária combinação ao princípio da excepcionalidade; e, por fim, a menção de condições pessoais do adolescente como impeditivas ao cumprimento de medidas em meio aberto. Ressalte-se que até mesmo a palavra "informal", referindo-se a um envolvimento anterior em outros atos infracionais, é mencionada como fundamento para a imposição da sanção mais severa do Estatuto.

O princípio da insignificância não pode ser transportado para a esfera da infância e juventude, no qual vige o princípio da proteção integral. Aliás, os procedimentos previstos para aplicação das medidas socioeducativas e protetivas previstas pelo Estatuto da Criança e do Adolescente não podem ser considerados constrangedores, pois visam justamente à aplicação do princípio da proteção integral.

Nesse discurso há um claro posicionamento que procura afastar da aplicação das medidas socioeducativas as regras e garantias processuais penais, utilizando-se do 
argumento de tratar-se de sistema diferenciado com fundamento na proteção integral. Além de desobedecer a regra do art. 152 do próprio Estatuto, que indica a aplicação subsidiária de outras normas em sua implementação, ele equipara as medidas socioeducativas a medidas protetivas, negando o caráter penal e sancionatório das primeiras. Sob o argumento da proteção integral, tal posição atualiza a chave tutelar discricionária nos procedimentos da Justiça da Infância e Juventude. É, sem dúvida, um exemplo categórico de decisionismo que faz uso dos princípios a depender de sua conveniência.

O tráfico de drogas deve ser considerado um dos atos infracionais mais graves, pois é prática que vem disseminando o vício entre a população mais vulnerável, ou seja, mais jovem e mais desprotegida da sociedade. O tráfico de drogas é ato infracional que pressupõe emprego de violência contra toda a sociedade.

Como se pode ver, a decisão procura justificar a imposição de medida de internação a ato infracional equiparado ao tráfico de drogas. Os argumentos utilizados partem da afetação do uso de drogas por crianças e adolescentes, desconsiderando a esfera da prevenção como a mais adequada ao enfrentamento do problema, e lançando à repressão ao indivíduo essa tarefa e finalidade. De outro lado, em descompasso ao posicionamento adotado pelo Superior Tribunal de Justiça (STJ), objetiva criar uma violência "presumida e ficta" contra toda a sociedade na prática do tráfico de drogas como forma de legitimação e adequação legal para a imposição da privação de liberdade.

No Tribunal de Justiça de Pernambuco, foram analisadas 11 decisões, das 13 ocorrências identificadas. Com destaque ao seguinte discurso:

... desajuste pessoal e propensão para a violência reclamam pronta e enérgica intervenção do Estado, com vistas a dar ao infrator a dimensão da reprovabilidade social que pesa sobre sua conduta, impondo-se a medida socioeducativa provisória, objetivando a garantia da integridade do próprio reeducando.

Nessa passagem, em que se discute a internação provisória e sua pertinência, a argumentação utiliza-se do discurso da proteção do adolescente para sua decretação, operando profunda confusão entre seu caráter e eventual medida protetiva que se faça necessária para garantir a integridade do adolescente. A mesma situação jamais seria admitida na justiça penal comum; um adulto não seria submetido a prisão preventiva sob o argumento de necessitar de proteção. É evidente que em tal situação o adolescente é submetido a condições mais severas do que um adulto seria. Também 
encontramos categorias estereotipadas de desajuste social e propensão à violência como características do adolescente.

Ainda sobre a internação provisória: “... construção jurisprudencial, considerando as peculiaridades do caso sub examinen, vem abrandando o posicionamento de que o prazo máximo de 45 (quarenta e cinco) dias a que alude o art. 108, do ECA, não pode ser ultrapassado sob nenhuma hipótese”. Aqui, em alusão ao prazo legalmente fixado pelo art. 108 do ECA, a decisão contrasta a previsão legal com construção jurisprudencial contra legem de extensão do referido prazo em prejuízo dos adolescentes acusados. Trata-se de flexibilização da única garantia de que goza o adolescente na seara da internação provisória.

Finalmente, de Pernambuco, dois aspectos merecem destaque: a negação da índole penal das medidas socioeducativas e, em consequência, do modelo de responsabilidade desenhado pelo ECA, para a administração de delitos praticados na adolescência, e a proposital alusão à educação e proteção como finalidades das medidas socioeducativas, o que favorece interpretações demagógicas da legislação, sempre em prejuízo e cerceamento da liberdade dos adolescentes. Também por isso se evoca a indeterminação do prazo de duração das medidas e o descabimento de regras e princípios processuais penais. Todos os elementos citados configuram um "neomenorismo" fundado na pretensa proteção e ausência de limites para a intervenção socioeducativa:

Isto porque o escopo do Estatuto da Criança e do Adolescente (Lei n. 8.069/90) não está ligado ao caráter punitivo da reprimenda. Ao contrário de visar a punição do menor infrator, pretende assegurar-lhe proteção e educação, através de medidas socioeducativas, sem critérios rígidos de duração. Assim como não é aplicada a pena prevista no delito análogo à infração praticada, também não há que se falar em aplicação de regras que são afetas à pena cominada, como atenuantes, e conduta social do adolescente sentenciado.

Junto ao Tribunal de Justiça do Rio de Janeiro foram identificadas 137 ocorrências relacionadas a medidas de internação das quais 58 foram estudadas. Dos discursos, merece destaque:

As condições pessoais do adolescente levam à conclusão que a medida de internação é a mais adequada e exigível à hipótese, dando-lhe melhores condições de ressocialização, estando destacado na sentença que: já the foram dadas oportunidades de cumprimento de medida em meio aberto em outros processos, mas o adolescente não as aproveitou, pois as descumpriu por várias vezes, reiteradamente descumpre as medidas impostas (grifo do autor). 
O trecho em grifo permite aferir que as condições pessoais do adolescente operam de forma mais intensa do que a verificação de sua conduta, configurando um direito penal do autor nos procedimentos da Justiça Especializada. Resta evidente que o que o adolescente é tem mais peso do que o que ele eventualmente tenha feito. Esse posicionamento pode ser identificado como uma releitura discricionária e subjetiva do ECA que dá margem a políticas repressivas e irracionais, tendo em vista que é o SER que é “atacado” e não o AGIR nas práticas infracionais.

A aplicação das socioeducativas estatuídas na lei n. 8.069/90 não possui caráter punitivo mas, sim, o de retirar o menor do convívio pernicioso com a criminalidade, visando reeducá-lo e reintegrá-lo à família e à sociedade.

Esse outro trecho demonstra posição que nega o caráter sancionatório das medidas socioeducativas e atribui à internação uma índole eminentemente segregadora, cuja tarefa é a retirada do convívio social.

Dois aspectos perigosos podem ser apontados, de um lado, a retirada da feição sancionatória das medidas pode levar à sua utilização irracional e ilimitada, e de outro, conceber a segregação como a principal tarefa da privação de liberdade afasta o desafio pedagógico que a medida deve contemplar.

A pesquisa referente ao Estado do Paraná identificou 123 casos relacionados à medida de internação em discussão no Tribunal de Justiça no recorte temporal previamente definido. Destes casos, 55 foram analisados em detalhe, e merece menção:

As medidas socioeducativas, por sua própria natureza, têm caráter pedagógico, e vinculam-se à sua finalidade essencial, que é a um só tempo, a reeducação e a ressocialização do menor infrator.

A decisão considera a natureza da medida socioeducativa como essencialmente pedagógica, negando-lhe a feição sancionatória e de reprovabilidade à conduta praticada.

Como já assinalado, esse tipo de posicionamento ignora o modelo de responsabilidade desenhado pelo ECA, para as infrações penais cometidas por adolescentes, assemelhando-o ao antigo Código de Menores.

O princípio do livre convencimento motivado do magistrado tem prevalência, ante a necessidade de se obter efetivamente o objetivo pedagógico pretendido com a aplicação da medida de internação.

Nesse trecho utiliza-se o princípio do livre convencimento do juiz como justificativa suficiente para a manutenção da internação. 
Nesse caso, incorre-se em equívoco, pois a livre convicção do juiz deve advir da confirmação pela pluralidade de provas e exige efetiva justificação da decisão. Como leciona Aroca, a valoração livre que cabe ao julgador não é igual à valoração discricional, nem se resume na consciência do juiz. Trata-se da forma como o juiz valora determinada prova, sendo que tal decisão deve expressar-se de modo motivado na sentença. No trecho supracitado o princípio é evocado sem que seja efetivamente implementado pela decisão.

Conduta do adolescente apelante evidencia o seu profundo desajuste social, impondo-se que se lhe ofereça a oportunidade de assimilar novos valores, reflita sobre o ocorrido, mediante acompanhamento intensivo que somente a internação possibilita.

Nesse discurso, assim como em outros já destacados, o argumento central repousa na ideia de desajuste social do adolescente. Essa categoria desvaloriza o papel da lei como critério exclusivo e exaustivo de definição dos fatos desviados. O adolescente é visto como delinquente a partir de um ponto de vista ético, naturalista, social e, em todo caso, ontológico.

A construção da ideia de periculosidade dos adolescentes é bastante frequente nos argumentos de justificação da internação, como se depreende neste trecho: "Alto nível de periculosidade do adolescente reforça ainda mais a necessidade de intervenção. Privado de liberdade o jovem aparenta bom comportamento; por outro lado, em meio aberto revelou atitudes totalmente divergentes daquelas apresentadas no Cense. Abandono da escola e usuário de drogas”. . Note-se que há uma efetiva criação da periculosidade social dos adolescentes, que passa a ser legalmente presumida e decorrente de condições pessoais ou de status social como "comportamento tendente à delinquência”, reincidência e até mesmo pertinência a determinados grupos de amigos.

No Tribunal de Justiça baiano foram identificados dezesseis casos versando sobre medida de internação no período estudado, destes treze foram analisados em profundidade. Dos discursos destaca-se:

... reprimir de forma mais severa tal conduta, em razão das consequências danosas à sociedade que o tráfico ilícito de entorpecentes vem causando, já que se trata não de ato infracional que atinge diretamente a bem jurídico de determinada pessoa, mas a toda a sociedade. Em sendo assim, exige-se o balanceamento de valores em oposição: de um lado o jus libertatis do indivíduo, que se revela, à primeira vista, perigoso, intranquilizando a comunidade; de outro, os interesses relevantes da sociedade, de manutenção da paz social, 
não sendo possível, no caso concreto, se permitir a reiteração da prática de tal ato infracional.

Como em outras decisões de Tribunais dos Estados que fizeram parte da pesquisa, o ato infracional equiparado ao crime de tráfico de entorpecentes, embora não comporte violência nem grave ameaça à pessoa, vem sendo reprimido com a imposição de medida de internação sob o argumento de tratar-se de crime hediondo o qual, tal como no trecho citado, afeta o bem jurídico de toda a sociedade. Essa tendência em coletivizar um suposto bem jurídico reflete aquilo que se convencionou chamar de expansão do direito penal, e configura uma espécie de relativismo jurídico, que dissolve o conceito de bem jurídico em múltiplos, casuais, contingentes, e até mesmo inconsistentes bens. Trata-se do que Ferrajoli denominou de utilização de termos vagos, imprecisos e valorativos, que derrogam a estrita legalidade dos tipos penais e permitem um amplo espaço à discricionariedade e à "inventiva" judicial, 21 o que não deveria ter guarida em um Estado democrático de Direito. Ademais, o trecho em questão também utiliza o etiquetamento do adolescente como perigoso para justificar a medida de internação: "Na espécie, cuida-se de conduta grave, com violência a pessoa, que revela desvio de personalidade acentuado por parte do adolescente e inadaptação ao meio, tendo aplicação o art. 122, inciso I, do ECA”.

Novamente categorias fundadas no desvio de personalidade e na inadaptação ao meio são evocadas para constituir uma periculosidade/perigosidade social que justifique a privação de liberdade.

O presente recurso deve ser provido. A reeducação do menor, um dos objetivos perseguidos pelo ECA pode ocorrer até que ele alcance 21 (vinte e um) anos. A demora na tramitação do feito não afasta a aplicação do ECA nem faz com que o Estado perca o interesse de agir, em razão do caráter pedagógico do Estatuto.

Nesse trecho identificado na Bahia o que está em jogo é o não reconhecimento da prescrição. Argumenta-se que em face do caráter pedagógico das medidas nunca se perde o interesse de agir até que o adolescente complete 21 anos. Tal posicionamento é contrario ao firmado pelo Superior Tribunal de Justiça na Súmula 338/STJ que inclusive remete aos parâmetros do Código Penal, especialmente a redução do art. 115 do mesmo Código.

Desse conjunto de discursos identificados como predominantes e, portanto, representativos da jurisprudência nacional nos Tribunais Estaduais pode-se aferir em primeiro lugar, aquilo que Gadamer denominou como ponto de partida essencial no método de interpretação: o pertencimento do intérprete a seu texto. Ou seja, o juiz não é livre para tomar distância histórica em relação a seu texto. ${ }^{22}$ 
Como já referido, a historicidade como característica inerente do "lugar e contexto" no qual se encontra o intérprete é formulada também por Gadamer como pilar de uma hermenêutica histórica. Para ele, não é a história que pertence a nós, mas nós é que a ela pertencemos, o que representa uma solução apenas aparente do problema que o conhecimento histórico nos coloca: "O homem é estranho a si mesmo e ao seu destino histórico de uma maneira muito diferente a como lhe é estranha a natureza, a qual não sabe nada dele". ${ }^{23}$

Muito antes que compreendamos a nós mesmos na reflexão, já estamos nos compreendendo de uma maneira autoevidente na família, na sociedade e no Estado em que vivemos. A lente da subjetividade é um espelho deformante. A autorreflexão do indivíduo não é mais que uma centelha na corrente cerrada da vida histórica. Por isso, os preconceitos de um indivíduo são, muito mais que seus juízos, a realidade histórica de seu ser. ${ }^{24}$

Gadamer ainda elucida que na conversação hermenêutica o texto só pode chegar a falar através do outro, o intérprete. Somente por ele se reconvertem os signos escritos de novo em sentido. Ao mesmo tempo, e em virtude dessa reconversão à compreensão, o próprio tema, de que fala o texto, vem à linguagem. Tal como nas conversações reais, é o assunto comum que une as partes entre si, nesse caso o texto e o intérprete. Como somente o tradutor, na qualidade de intérprete, torna possível o acordo numa conversação, em virtude do fato de participar na coisa de que está tratando, também face ao texto, é pressuposto iniludível do intérprete que ele participe de seu sentido. ${ }^{25}$

No que toca as visões que sobressaem acerca da adolescência, da prática de infrações penais e do papel e finalidade das sanções, devemos ter em mente que toda motivação de uma decisão é, antes, uma tentativa de persuasão, sendo certo também, como adverte Perelman, que nada garante que cada juiz esteja perfeitamente consciente de todos os móbeis que o inclinam para certa solução. ${ }^{26}$ Vale dizer que, a própria ideia de motivação, de justificação de uma decisão, muda de sentido ao mudar de auditório:

Enquanto pela motivação o juiz só tinha de justificar-se perante o legislador, mostrando que não violava a lei, bastava-lhe indicar os textos que aplicava em sua sentença. Mas, se a motivação se dirigir à opinião pública, esta quererá, além disso, que a interpretação da lei pelo juiz seja o mais conforme possível tanto à equidade, quanto ao interesse geral. ${ }^{27}$

No escólio de Perelman, motivar uma sentença é justificá-la de modo demonstrativo, ou seja, de forma a persuadir um auditório, e o Direito passa a ser, simultaneamente, ato de autoridade e obra de razão e de persuasão. Como exercício de um poder, há sempre a possibilidade de uma escolha razoável entre várias soluções, sendo certo que tal escolha inevitavelmente dependa de um juízo de valor. 
De modo geral, acredita-se que o juiz preste contas na motivação para os ouvintes a que se dirige e conforme o papel que cada jurisdição deve cumprir. Igualmente, acredita-se que os tribunais inferiores se justifiquem perante as partes, a opinião pública e, sobretudo, às instâncias superiores que podem exercer papel de controle em casos de recursos.

Dos discursos recolhidos para este artigo, não se pode afirmar que os tribunais estaduais estejam efetivamente preocupados em justificar-se perante o Superior Tribunal de Justiça (STJ) que, via de regra, vem apresentando uma tendência bem mais receptiva aos pleitos da defesa dos adolescentes. Conforme já assinalado por Flávio Frasseto, ${ }^{28}$ um olhar apurado sobre os julgados indica, de um lado, a receptividade da Corte Federal aos reclamos da defesa e, de outro, que os graus inferiores da Justiça não têm guardado com a fidelidade esperada os direitos outorgados aos jovens que poderão receber ou que já receberam medidas socioeducativas.

\section{CONCLUSÃO}

É comum no campo da hermenêutica jurídica definir o juiz, na qualidade de intérprete, como um mediador entre as partes que procedem reciprocamente como antagonistas em um conflito soma zero: a situação típica inicial em um litígio civil ou comercial de direito privado. Entretanto, o mesmo não pode ser dito em face dos conflitos de natureza penal que emergem afetando bens jurídicos, e, em consequência, geram do ponto de vista do Estado a chamada pretensão punitiva, o objetivo e interesse em perseguir e punir o ato antinormativo - a conduta praticada. Essa situação reflete em gênero, número e grau a dinâmica de apuração de responsabilidade e imposição de medida socioeducativa a um adolescente.

Considerando que a discussão teórica em torno da interpretação do Direito conduz a uma dupla e divergente abordagem. Na perspectiva subjetivista, a interpretação é atividade dirigida ao reconhecimento da vontade do legislador, no sentido inverso é uma atividade que se destina a elucidar o sentido normativo da lei na perspectiva objetivista, no caso, do Estatuto da Criança e do Adolescente. Dado seu caráter "revolucionário" de ruptura com o modelo anterior, tende-se a privilegiar a vontade do legislador e as soluções legislativas sobre as judiciais, com tendências nitidamente subjetivistas. É o que em sua maioria espelha a doutrina contemporânea especializada, que confere enorme ênfase à letra da lei e à intenção do legislador do Estatuto, desconsiderando que também nessa busca realiza-se interpretação.

Em direção oposta, o Judiciário posiciona-se como espaço de revelação do sentido normativo da norma, tendo em vista seu papel de articulador da lei ao contexto social no qual a mesma incide.

Na medida em que a interpretação opera a historicização da norma, a interpretação da lei nunca é o ato solitário de um magistrado ocupado, como adverte Pierre 
Bourdieu, ${ }^{29}$ mas trata-se de uma luta simbólica entre profissionais dotados de competências técnicas e sociais desiguais, capazes de mobilizar, também de modo desigual, os meios ou recursos jurídicos. ${ }^{30}$ A hermenêutica jurídica é, dessa maneira, reforçada como consequência da inegável dimensão argumentativa do direito.

Em outras palavras, trata-se de reconhecer que a atividade hermenêutica, seja ela de apreensão do sentido normativo, seja de complementação de significados - no caso de lacunas ou conflitos de normas -, tem sempre de ser argumentada a partir do próprio direito vigente. Isso que significa adotar um pressuposto básico de caráter normativo e, ao mesmo tempo, admitir que os conceitos normativos "pedem" do decididor uma coparticipação na determinação de seu sentido.

Ocorre que muitas vezes, e assim se dá no campo da interpretação do Estatuto da Criança e do Adolescente, os juízes se refugiam no papel de intérprete que apenas realiza uma simples aplicação da lei, e quando realizam obra de criação jurídica tendem a dissimulá-la. ${ }^{31} \mathrm{O}$ enaltecimento do ato de interpretação visa sublimar a decisão, demonstrando que ela exprime não a vontade e a visão de mundo do juiz, mas sim a voluntas legis ou legislatoris.

As duas concepções da interpretação são em verdade insatisfatórias. Enquanto a perspectiva subjetivista se concentra na revelação da vontade do legislador, ela acaba por encobrir, em uma suposta atividade de historiador, o papel criativo daquele que decide. Em contrapartida, a concepção objetivista da interpretação se arrisca a substituir a vontade do legislador pela do juiz e a suprimir a diferença entre a regra que foi promulgada e aquela que se queria ver instaurar. ${ }^{32}$

Certo é que o juiz decide, resolve, escolhe, e o faz em nome do que considera o direito; a justiça, sabendo que suas decisões vão integrar-se no sistema de direito de que eles constituem um elemento central. Nesse contexto, as técnicas de interpretação, justificadas pelo recurso à lógica jurídica, que não é uma lógica formal mas uma lógica do razoável, representam um auxílio essencial na medida em que permitem que os juíz conceituem, por uma argumentação apropriada, o que lhe dita seu senso de equidade e seu senso do direito.

$\mathrm{Na}$ interpretação do Estatuto da Criança e do Adolescente, fica evidente o papel crescente do juiz na elaboração do direito, tendo em vista inclusive a textura aberta da legislação e a presença marcante de princípios que carecem de maior regulamentação ou preenchimento de sentido, labor que o legislador deixou a cargo do juiz.

A opção principiológica do legislador estatutário responde à dinâmica e ao contexto político de elaboração da norma. Como já mencionado, o ECA promove uma "revolução" jurídica, na medida em que reconhece direitos a crianças e adolescentes, na qualidade de sujeitos de direitos, quando outrora estavam excluídos por completo das prioridades e finalidades do Estado.

Essa técnica legislativa posterga de certa forma a atividade legiferante para situações limite, já que ao intérprete cabe a adequação do princípio ao caso concreto. Em outras 
palavras, significa dizer que o juiz, ao decidir, legisla diante do elevado número, por exemplo, de princípios estatutários ainda não regulamentados.

É conforme analisa Perelman, "a dialética entre o legislativo e o poder judiciário, entre a doutrina e a autoridade, entre o poder e a opinião pública, que faz a vida do direito e lhe permite conciliar a estabilidade e a mudança”. ${ }^{33}$

$\mathrm{Na}$ esteira do pensamento habermasiano, cabe destacar que existe, tal qual advertiu Gadamer, uma inegável incindibilidade entre aplicação e interpretação e, de igual maneira, não há como separar o Direito da Moral. ${ }^{34}$

A redução do direito à lei, ou a chamada "absolutização da norma" no dizer de Heron Gordilho, ${ }^{35}$ permite constatar que positivação e decisão podem ser vistas como termos correlatos; e mesmo as tentativas modernas de fazer da ciência jurídica uma ciência da norma, como se dá na Teoria Pura kelseniana, não lograram afastar o problema do comportamento humano e suas implicações na elaboração e aplicação do direito. Assim, os intentos em separar o direito e os demais fenômenos culturais, como a política, a religião e a economia, não são capazes de se sustentar em face das limitações do pensamento científico-jurídico.

Na pós-modernidade, o Direito é desafiado a encarar o mito da neutralidade, uma vez que o objeto central da Ciência do Direito não é nem a positivação, nem o conjunto das normas positivas, mas o próprio homem que, do interior da positividade jurídica que o envolve, se representa, discursivamente, no sentido das normas ou proposições prescritivas que ele mesmo estabelece, obtendo, afinal, uma representação da própria positivação. A abordagem jurídica pós-moderna aproxima o Direito da sociologia, pois enquanto aquela cuida dos objetos culturais na lógica do ser, o Direito cuida dos objetos culturais na lógica do dever ser.

Outra constatação importante está no reconhecimento do papel da doutrina como precioso instrumento auxiliar da justiça, no sentido de fornecer as justificações que permitam restringir ou ampliar o alcance das regras de direito de uma forma aceitável pelas Cortes e Tribunais. É na medida em que elas fornecem as razões de uma solução aceitável que serão adotadas pela jurisprudência. As cortes se empenham, através de sua argumentação, em convencer os legisladores, os juízes e a opinião pública de que, sobre esses dois pontos, o caráter aceitável das soluções e o valor das justificações são preferíveis às concepções concorrentes.

Nesse aspecto a fragilidade da doutrina jurídico-penal na área de infração penal praticada por adolescentes é, sem dúvida, uma das razões para a informalidade dos procedimentos que resultam em privação da liberdade. Acredita-se que seja possível atribuir, parcialmente, esse procedimento a um sistema anterior que limitava a abordagem do direito a poucos e imprecisos dispositivos procedimentais. Como se pôde constatar, para a boa doutrina penal brasileira, a questão se resumia, praticamente, ao bom senso e à prudência do magistrado (nem sempre presentes). As atitudes subjetivas supririam qualquer outro cuidado externo por parte do poder público. Não 
havia desta forma, como construir um corpo doutrinário nem formar intérpretes e doutrinadores sobre tais bases. Esse legado de exagerada atitude assistencial tem permitido que, mesmo sob a égide do Estatuto, as práticas judiciais atuais sejam ainda inspiradas, muitas vezes, no modelo anterior. Ou seja, a hesitação em adotar um modelo amplamente garantista para o adolescente tem permitido a discricionariedade na apuração da infração praticada e a consequente aplicação da medida.

Como se pode perceber da análise realizada neste artigo, em seus vinte anos de vigência, o Estatuto da Criança e do Adolescente vem sendo interpretado de forma bastante homogênea pela jurisdição de primeiro grau, através de entendimentos em geral contrários aos principais pleitos da defesa. Observa-se uma inquestionável tendência de negação às suas teses na maioria dos Tribunais, e uma cristalização de procedimentos irregulares se contrastados ao texto da Lei.

Não são poucos os exemplos que denotaram um automatismo na aplicação da medida de internação em desconsideração inclusive a regras expressamente indicadas pela legislação, como é o caso do princípio da excepcionalidade.

Nota-se, de um lado, a dificuldade de superação da herança kelseniana do decisionismo e, de outro, que a discricionariedade foi reapropriada pelos procedimentos argumentativos, ou seja, sob o manto de uma racionalidade argumentativa ainda prevalece a subjetividade do decididor.

Finalmente, poder-se-ia atribuir a essa realidade interpretativa as dificuldades inerentes de uma legislação principiológica, posto que os princípios permitem uma comunicação mais aberta, um número indefinido de hipóteses, uma racionalidade material e não apenas lógico-formal e, inevitavelmente, enfrentam maiores dificuldades na formação e consolidação da jurisprudência.

O fato é que os juízes podem explorar com um grau substantivo de liberdade, a polissemia, as ambiguidades, as lacunas, e a elasticidade da legislação, resultando na aplicação e utilização das medidas de internação como intervenção psicossocial destinada a modificar o sujeito em franco alheamento às regras e princípios processuais penais de garantia. As medidas socioeducativas aplicadas sem a observância do devido processo legal e do contraditório, constituem uma ferramenta de reforço da exclusão a que muitos ou a esmagadora maioria dos adolescentes estão expostos. A ironia é que no momento de sua imposição, as medidas socioeducativas se sustentam num discurso compensatório, já que os adolescentes envolvidos com a prática de infrações penais sempre revelam em alguma fase de sua vida direitos negligenciados, desde famílias problemáticas, violência doméstica, baixa escolaridade, defasagem escolar, precária inserção no mercado de trabalho, abandono e vivência institucional em abrigos ou vivência de rua.

Essa realidade nos remonta ao que Luigi Ferrajoli definiu como ideologia correcional. Historicamente, as doutrinas e legislações penais de tipo genuinamente correcional se desenvolveram na segunda metade do século XIX, paralelamente à 
difusão de concepções organicistas do corpo social, o são e o enfermo, acerca das quais são chamados a exercitar-se o olho clínico e os experimentos terapêuticos do poder. É quando o projeto ilustrado e puramente humanitário de castigar menos se converte no projeto disciplinar e tecnológico de castigar melhor. ${ }^{36}$

Da interpretação e do discurso predominante podemos facilmente identificar a visão da sanção jurídico-penal como medicina da alma - mais um bem que um mal para quem a sofre -, e finalmente identificar no funcionamento da Justiça da Infância e Juventude, e secundariamente dos Tribunais, uma forma atualizada de pedagogismo penal.

: ARTIGO APROVADO (15/01/2011) : RECEBIDO EM 30/07/2010

\section{NOTAS}

1 É importante desde logo assinalar que a homogeneidade a que nos referimos reflete uma tendência em não acolher os pleitos da defesa dos adolescentes acusados, e, na maioria dos casos, dar provimento à asseveração das sanções como postula o Ministério Público na acusação.

2 O reconhecimento de variadas possibilidades interpretativas não é novidade no âmbito da Teoria do Direito. Mesmo Kelsen admite que a atividade de interpretação resulte em uma decisão dentre outras possíveis, não havendo, portanto, uma decisão única e correta. Apesar de seu formalismo positivista, revela uma visão metaética subjetivista e, portanto, relativista da justiça chegando a afirmar que o juízo através do qual julgamos algo como justo não pode jamais pretender excluir a possibilidade de um juízo de valor oposto. A justiça absoluta lhe parece assim um ideal irracional. Em síntese, para Kelsen a interpretação que é realizada pelo órgão aplicador do Direito, sendo sempre autêntica, cria o Direito: "na aplicação do Direito por um órgão jurídico, a interpretação cognoscitiva (obtida por uma operação de conhecimento) do Direito a aplicar combina-se com um ato de vontade em que o órgão aplicador do Direito efetua uma escolha entre as possibilidades reveladas através daquela mesma interpretação cognoscitiva”. Portanto, o direito a ser aplicado representa um simples marco no interior do qual existem várias possibilidades de aplicação, sendo que todo ato que se ajuste ao marco é considerado adequado (Hans Kelsen, Teoria pura do direito, 3. ed., São Paulo: Ed. Martins Fontes, 1991).

3 Numerosos são os exemplos de comparação entre o Direito e o jogo realizada tanto por sociólogos, antropólogos e também por teóricos do direito. Alf Ross, ao estudar a validade das normas jurídicas, evoca uma ideia de validade das regras de um jogo social. Hart propõe uma distinção entre as regras jurídicas inspirando-se nas regras dos jogos esportivos (adesão à regra, sanção, arbitragem). Outra abordagem possível é aquela preconizada por Pierre Bourdieu ao descrever o "espaço judicial” pela imposição de uma fronteira entre os que estão preparados para entrar no jogo e os que não podem operar a conversão de todo o espaço mental - em particular de toda a postura linguística -, que supõe a entrada nesse espaço social (Pierre Bourdieu, O poder simbólico, 4. Ed., Rio de Janeiro: Bertrand Brasil, 2001).

4 CAVAliERI, Alyrio. (Org.) Falhas do Estatuto da Criança e do adolescente. Rio de janeiro: Ed. Forense, 1997.

5 Essa particularidade que os autores anglo-saxões qualificam de "textura aberta" da linguagem ordinária (open texture) sinaliza a existência de uma zona de penumbra que rodeia o núcleo de sentido claro de um conceito (Hart, The 
Concept of Law. p.121ss apud Karl Larenz, Metodologia da Ciência do Direito, 3. ed., Lisboa: Fundação Calouste Gulbenkian, 1997, p. 413).

6 Sob coordenação da Professora Doutora Maria Auxiliadora de Almeida Minahim, com a participação dos pesquisadores: Karyna Batista Sposato (pesquisadora sênior); Davi Castro Silva (assistente de pesquisa); Carolina Grant Pereira,Deivson Santos e Natália Petersen (estagiários de pesquisa).

7 A primeira etapa da pesquisa jurisprudencial adotou como metodologia a pesquisa quantitativa por amostragem aleatória simples. O estudo qualitativo acerca da Justiça de $1^{\circ}$ Grau, no tocante à apuração de ato infracional praticado por adolescente e a imposição de sentenças de internação, foi realizado mediante o acompanhamento de 15 audiências e analise de 14 processos em São Paulo, 15 audiências e análise de 15 processos em Salvador, 12 audiências e 11 processos em Porto Alegre, e 12 audiências e 13 processos em Recife.

8 MENDEZ, Emilio Garcia. Evolución histórica del Derecho de la Infancia: Por que uma historia de los derechos de La infancia?. In: Justiça, Adolescente e Ato Infracional: socioeducação e responsabilização. São Paulo, Brasil: Ilanud, 2006.

9 Em um grande número de casos os argumentos da proteção da sociedade e da autoproteção do adolescente são invocados como fundamentação para a imposição da privação de liberdade.

10 A consciência histórica efeitual na formulação de Gadamer representa a tomada de consciência da própria consciência histórica de que, na suposta imediatez com que se orienta para a obra ou para a tradição, estão sempre em jogo outros questionamentos, ainda que de maneira despercebida e, em consequência, incontrolada. Quando procuramos compreender um fenômeno histórico a partir da distância histórica que determina nossa situação hermenêutica como um todo, encontramo-nos sempre sob os efeitos dessa história efeitual. Ela determina de antemão o que se mostra a nós como questionável e como objeto de investigação, e nós esquecemos logo a metade do que realmente é, mais ainda, esquecemos toda a verdade desse fenômeno cada vez que tomamos o fenômeno imediato como toda a verdade. A consciência da história efeitual é, em primeiro lugar, a consciência da situação hermenêutica (Hans-Georg Gadamer, Verdade e método I -Traços fundamentais de uma hermenêutica filosófica, 3. ed. Bragança Paulista/São Paulo: Editora Universitária São Franscisco, 1999).

11 PIRES, Alvaro Penna. Alguns Obstáculos a uma Mutação "humanista" do Direito Penal. In: Sociologias, Revista do Programa de Pós-Graduação em Sociologia da UFRGS (semestral). n. 1. Dossiê Conflitualidades, Porto Alegre, 1999.

12 Dados recentes da Subsecretaria de Promoção e Defesa dos Direitos da Criança e do Adolescente (SPDCA) da Secretaria Especial de Direitos Humanos (SEDH) demonstram que o percentual de adolescentes em cumprimento de medidas judiciais não ultrapassa $0,15 \%$ da população de adolescentes. O universo de adolescentes infratores é bem mais restrito que o dos adultos. As estatísticas nacionais revelam ainda a predominância dos delitos patrimoniais. Seja em relação aos adolescentes privados de liberdade no país, seja dentre aqueles acusados da autoria de atos infracionais.

13 É significativa e cíclica a presença de projetos de lei e de propostas de Emenda Constitucional no Congresso Nacional Brasileiro, objetivando alterar dispositivos constitucionais e do Estatuto da Criança e do Adolescente, em resposta a clamores sociais e da opinião pública, sobretudo, quando um crime de repercussão nacional revela dentre os autores a presença de um adolescente menor de 18 anos.

14 Não se trata aqui de negar o ordenamento jurídico como sistema aberto e móvel, tal qual descreveu Claus Wiheim Canaris, ao considerá-lo como conjunto de normas cuja interpretação está em constante movimento (Claus Wilheim Canaris, Pensamento Sistemático e Conceito De Sistema na Ciência do Direito, Lisboa: Fundação Calouste Gulbenkian, 1996). Tampouco desprezamos o importante papel da jurisprudência na criação do Direito, porém, nos associamos ao pensamento garantista de Luigi Ferrajoli, de que a ausência de normas nunca é neutra, a ausência de normas é sempre a regra do mais forte (Luigi Ferrajoli, Derecho y Razón - Teoria del Garantismo Penal, 4. ed., Madrid: Editorial Trotta, 2000).

15 O Estatuto da Criança e do Adolescente em seu art. 112 exige rigoroso nexo de causalidade entre a conduta praticada pelo adolescente e o dano causado. A conduta dolosa ou ao menos culposa que atentou contra bens jurídicos protegidos em normas incriminadoras é, ao lado da lesão ao bem jurídico, o critério para a imposição de medida socioeducativa. A verificação da prática de um ato infracional não é condição suficiente para a imposição de uma medida privativa da liberdade, a qual somente é admitida na inexistência de outra mais adequada. Advertência, obrigação de 
reparar o dano, prestação de serviços à comunidade, liberdade assistida, inserção em regime de semiliberdade, e internação em estabelecimento educacional são os tipos de medidas previstas pelo Estatuto, em linha crescente de severidade, ou interferência na liberdade individual dos adolescentes a quem se atribui a autoria da infração. Dividem-se em medidas não privativas de liberdade (advertência, reparação de dano, prestação de serviços à comunidade e liberdade assistida) e medidas privativas de liberdade (semiliberdade e internação). Assim como a imposição de pena exige a demonstração inequívoca de autoria e materialidade, o mesmo se estabelece para as medidas socioeducativas, consoante o art. 114 da Lei 8.069/90: "A imposição das medidas previstas nos incisos II a IV do artigo 112 pressupõe a existência de provas suficientes da autoria e da materialidade da infração, ressalvada a hipótese de remissão, nos termos do artigo 127”. É importante sublinhar ainda que, afora todos os princípios penais e especiais que incidem no Direito Penal Juvenil, o Estatuto da Criança e do Adolescente é expresso ao recomendar a aplicação preferencial de medidas que não prejudiquem a socialização dos adolescentes, conforme art. 100 da Lei: "Na aplicação das medidas levar-se-ão em conta as necessidades pedagógicas, preferindo-se aquelas que visem ao fortalecimento dos vínculos familiares e comunitários”.

16 SOTOMAYOR ACOSTA, Juan Oberto. Inimputabilidad y Sistema Penal. Santa Fé de Bogotá: Editorial Temis, 1996.

17 GARRIDO DE PAULA, Paulo Afonso. Direito da Criança e do Adolescente e tutela jurisdicional diferenciada. São Paulo: Revista dos Tribunais, 2002.

18 Adotamos aqui a expressão "Direito Penal Juvenil" para designar a matéria correspondente à atribuição de responsabilidade a adolescentes autores de ato infracional que integra a normativa da Criança e do Adolescente. Para mais detalhes ver Karyna Batista Sposato. O direito penal juvenil. São Paulo: Ed. Revista dos Tribunais, 2006.

19 GARRIDO DE PAULA, Paulo Afonso. Op. cit.

20 "Durante o período de internação, inclusive provisória, serão obrigatórias atividades pedagógicas" (art. 123, parágrafo único da Lei 8.069/90).

21 FERRAJOLI, Luigi. Derecho y Razón : Teoria del Garantismo Penal. 4. ed. Madrid: Editorial Trotta, 2000.

22 GADAMER, Hans-Georg. Verdade e método II - Complementos e índice. 3. ed.. Bragança Paulista/São Paulo: Ed. Universitária São Franscisco, 2007, p.58.

23 GADAMER, Hans-Georg. Idem, ibidem, p.58.

24 A ideia de preconceito em Gadamer repousa no conceito de preconceito como ponto de partida. Uma análise da história do conceito mostra que é somente no Aufklàrung que o conceito do preconceito recebeu o matiz negativo que agora possui. Em si mesmo, "preconceito" (Vorurteil) quer dizer um juízo (Urteil) que se forma antes da prova definitiva de todos os momentos determinantes segundo a coisa. No procedimento jurisprudencial um preconceito é uma pré-decisão jurídica, antes de ser baixada uma sentença definitiva. Para aquele que participa da disputa judicial, um preconceito desse tipo representa, evidentemente, uma redução de suas chances. Por isso, préjudice, em francês, tal como praejudicium, significa também prejuízo, desvantagem, dano. Não obstante, essa negatividade é apenas secundária. É justamente na validez positiva, no valor prejudicial de uma pré-decisão, tal qual o de qualquer precedente, que se apóia a consequência negativa. "Preconceito" não significa de modo algum falso juízo, pois está em seu conceito que ele possa ser valorizado positivamente ou negativamente. É claro que o parentesco com o praejudicium latino torna-se operante nesse fato, de tal modo que, na palavra, junto ao matiz negativo, pode haver também um matiz positivo. Dessa forma, preconceitos podem corresponder à despotenciação da tradição. O que na formulação kantiana representa a coragem de te servir de teu próprio entendimento.

25 GADAMER, Hans-Georg. Op. cit.

26 PERELMAN, Chaim. Ética e direito. Tradução por Maria Ermantina Galvão. São Paulo: Ed. Martins Fontes, 1996, p. 560 .

27 PERELMAN, Chaim. Op. cit., p. 560.

28 FRASSETO, Flávio Américo. Ato infracional, medida socioeducativa e processo: A nova Jurisprudência do Superior Tribunal de Justiça. Disponível em: <www.abmp.org.br/sites/frasseto>. 
29 BOURDIEU, Pierre. Op. cit., p. 219.

30 BOURDIEU, Pierre. Idem, ibidem, p. 219.

31 BOURDIEU, Pierre. Idem, ibidem, p.219.

32 PERELMAN. CHAIM. Idem, ibidem, p. 624.

33 PERELMAN. CHAIM. Idem, ibidem, p. 631.

34 PERELMAN. CHAIM. Idem, ibidem, p. 631.

35 HABERMAS, Jürgen. Direito e Democracia- entre facticidade e validade - vol. 1 - Tradução por Flávio Bueno Siebeneichler. Rio de Janeiro: Ed. Tempo Brasileiro, 1997, p.191.

36 GORDILHO, Heron José de Santana. Por uma dogmática Pós-Moderna. In: Revista do Programa de PósGraduação em Direito da Universidade Federal da Bahia - Homenagem ao Prof. Orlando Gomes, 2008.

37 FERRAJOLI, Luigi. Derecho y Razón : Teoria del Garantismo Penal. 4. ed. Madrid: Editorial Trotta, 2000.

\section{REFERÊNCIAS BIBLIOGRÁFICAS}

BOURDIEU, Pierre. O poder simbólico. 4. ed. Rio de Janeiro: Bertrand Brasil, 2001.

BUSTOS RAMIREZ, Juan; HORMAZÁBAL MALARÉE, Hernán. Nuevo Sistema de Derecho Penal. Madrid: Editorial Trotta, 2004.

. Introducción Al Derecho Penal. Santa Fé de Bogotá: Editorial Temis, 1994.

CANARIS, Claus Wilheim. Pensamento Sistemático e Conceito de Sistema na Ciência do Direito. Lisboa: Fundação Calouste Gulbenkian, 1996.

CAVALIERI, Alyrio. (Org.) Falhas do Estatuto da Criança e do Adolescente. Rio de Janeiro: Ed. Forense, 1997. CURY. Munir. Estatuto da Criança e do Adolescente anotado. 2. ed. São Paulo: Ed. Revista dos Tribuanais, 2000. FERRAJOLI, Luigi. Derecho y Razón - Teoria del Garantismo Penal. 4. ed. Madrid: Editorial Trotta, 2000.

FERRAZ JR., Tércio Sampaio. A ciência do Direito. 2. ed. São Paulo: Ed. Atlas, 1980. Introdução ao estudo do Direito - Técnica, decisão, dominação. São Paulo: Ed. Atlas, 1988.

FRASSETO, Flávio Américo. Ato infracional, medida socioeducativa e processo: A nova jurisprudência do

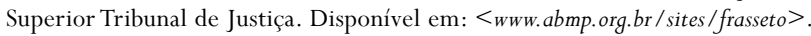

GADAMER, Hans-Georg. Verdade e método I - Traços fundamentais de uma hermenêutica filosófica. 3. ed. Bragança Paulista/São Paulo: Ed. Universitária São Franscisco, 1999.

. Verdade e Método II: complementos e índice. 3. ed. Petrópolis/Rio de Janeiro: Ed. Vozes, 2007.

GARRIDO DE PAULA, Paulo Afonso. Direito da Criança e do Adolescente e tutela jurisdicional diferenciada. São Paulo: Ed. Revista dos Tribunais, 2002.

GORDILHO, Heron José de Santana. Por uma dogmática Pós-Moderna. Revista do Programa de Pós-Graduação em Direito da Universidade Federal da Bahia, homenagem ao Prof. Orlando Gomes, 2008.1.

GROSSI, Paolo. Mitología Juridica de la Modernidad. Madrid: Editorial Trotta, 2003.

HABERMAS, Jürgen. Direito e semocracia - Entre facticidade e validade. Tradução por Flávio Bueno Siebeneichler. Rio de Janeiro: Ed. Tempo Brasileiro, 1997. Vol. 1.

HART, Herbert L. A. O conceito do direito. 5. ed. Lisboa: Fundação Calouste Gulbenkian, 2007.

KELSEN, Hans. Teoria pura do direito. 3 ed. São Paulo: Ed. Martins Fontes, 1991.

LARENZ, Karl. Metodologia da Ciência do Direito. 3. ed. Lisboa: Fundação Calouste Gulbenkian, 1997. LECHNER, Norbert. Los Pátios Interiores de la Democracia: Subjetividad y Política. 2. ed. México/DF: Fondo de Cultura Econômica, 1995.

MENDEZ, Emilio Garcia. Infancia : de los Derechos a la Justicia. 1. Ed. Buenos Aires: Editores Del Puerto, 2004. Evolución histórica del Derecho de La Infancia: Por que uma historia de los derechos de la infancia? In: Justiça, Adolescente e Ato Infracional: Socioeducação e Responsabilização. XXXX: Ilanud, 2006. 
MUÑOZ CONDE, Francisco; HASSEMER, Winfried. Introducción a la Criminologia. Valencia: Tirant lo Blanch, 2001. NINO. Carlos S. Justicia. In: VALDÉS, Ernesto Garzón; LAPORTA, Francisco J. (Orgs.) El Derecho y la Justicia. 2. ed. Madrid: Editorial Trotta, 2000.

ORTEGA Y GASSET, José. O homem e a gente - Intercomunicação humana. 2. ed. Rio de Janeiro: Livro Ibero-Americano. OST, François; KERKOVE, Michel van de. Elementos para uma Teoria Crítica del Derecho. Bogotá: Editorial Unibiblos, 2001. Colección Teoria y Justicia - Universidad Nacional de Colombia/Facultad de Derecho, Ciencias Politicas y Sociales.

PERELMAN, Chaim. Ética e direito. Tradução por Maria Ermantina Galvão. São Paulo. Ed. Martins Fontes, 1996. Tratado da Argumentação: a nova retórica. Tradução por Maria Ermantina Galvão. 2. ed. São Paulo: Ed. Martins Fontes, 2005.

PIRES, Alvaro Penna. Alguns Obstáculos a uma Mutação "humanista" do Direito Penal. Sociologias - Revista semestral do Programa de Pós-Graduação em Sociologia da UFRGS, 1, n. 1, Dossiê Conflitualidades, Porto Alegre, 1999.

REALE, Miguel. O direito como experiência. Introdução à epistemologia jurídica. 2. ed. São Paulo: Ed. Saraiva, 1992. SOTOMAYOR ACOSTA, Juan Oberto. Inimputabilidad y Sistema Penal. Santa Fé de Bogotá: Editorial Temis, 1996. SPOSATO, Karyna Batista. O direito penal juvenil. São Paulo: Ed. Revista dos Tribunais, 2006.

Culpa e castigo: modernas teorias da culpabilidade e limites ao poder de punir. Revista Brasileira de Ciências Criminais, n. 56. set./out. 2005.

STRECK, Lenio Luiz. Verdade e consenso - Constituição. hermenêutica e teorias discursivas, da possibilidade à necessidade de respostas corretas em direito. 3. ed. Rio de Janeiro: Ed. Lumen Iuris, 2009.

VERNENGO, Roberto J. Interpretación del Derecho. In: VALDÉS, Ernesto Garzón; LAPORTA, Francisco J.

(Orgs.) El Derecho y la Justicia. 2. ed. Madrid: Editorial Trotta, 2000.

WARAT, Luis Alberto. Epistemologia e ensino do direito: o sonho acabou. Florianópolis: Fundação Boiteaux, 2004.

\section{Maria Auxiliadora Minahim}

Rua da Paz s/n Graça - 40150-140 Salvador - BA - Brasil minahimaufba.br

Rua François Hoald, 495 Atalaía - 49.037-000 Aracaju - Sergipe - Brasil karyna_sposatolaunit.br
Professora Associada da Universidade Federal DA BAHIA (UFBA), FACULdAdE dE DIREITO, Departamento de Direito Público

Membro do Conselho de Direitos humanos da Bahia Presidente Nacional da Associação Brasileira de Professores de CIÊnCIAs Penais (ABPCP)

\section{Karyna Batista Sposato}

Professora do Curso de Direito e Pesquisadora do Núcleo de Pós-Graduação em Direito (NPGD) DA UNIVERSIDADE TIRADENTES (UNIT)

Doutoranda PELA Universidade Federal da Bahia E PELA Universidade Pablo de Olavide / Sevilha / Espanha)

Coordenadora Estadual da Associação Brasileira de Professores de Ciências Penais (ABPCP) em Sergipe 